\title{
Application of Organic Silicone Antifreeze in the Temperature Measurement System of Transformer
}

\author{
Qinghao Wang, Chenyang Liu, Enlu Wang, Wenguang Zhang, \\ Xiaoshu Zhang, Qiang Zhao, Feng Shi, Jiatong Sun, Changxin Ge \\ Fushun Power Supply Company, Liaoning Electric Power Company Limited, State Grid, China
}

Keywords: Temperature Measuring Hole; Transformer Oil; Insulating Material; Temperature Rise; Special Anti Freezing Agent

\begin{abstract}
Transformer in the operation process, iron core, winding and steel structure to produce loss. These losses will produce heat, leading to the transformer temperature rise, the aging of insulation materials to accelerate, the transformer's service life is shortened. In order to ensure that the temperature of each component of the transformer is not more than the limit value, the service life of the transformer is prolonged, and the temperature measuring device must be installed. The temperature measuring device is used to monitor the temperature and temperature change of the transformer. The existing temperature measuring device has the problem of bad sealing, and the water enters the temperature measuring device through the temperature measuring hole. In winter, the water is converted into ice, and the thermometer is easily cracked, leading to the failure of the function of the temperature measuring device. An effective method is described in this paper to avoid the thermometer being ruptured. Because the performance and density of anti freezing agent is better than that of transformer oil, special anti freeze agent is used to replace transformer oil in the temperature measuring hole. So, completely solve the problem of the thermometer damage accident.
\end{abstract}

\section{Introduction}

Transformer is a kind of static electrical equipment, it can be a level of AC voltage into the same frequency of one or more voltage levels of the AC voltage, but does not change the capacity of transmission. Transformers are widely used in various fields of daily production and daily life. In the electric power system, it is not feasible to use the low voltage to transmit the power at long distance. In the use of low voltage transmission of electric energy, its running current is very large, in the transmission line with a very large power loss and voltage drop, and ultimately lead to electrical energy can not be transported out. For example: in the $10 \mathrm{kV}$ transmission line voltage conditions, the power of the $3000 \mathrm{~kW}$ power generator, the most remote can only be transported to a dozen kilometers of distance. Insulation technology is more difficult to implement in the process of producing high voltage generator. Therefore, only by using the transformer, the line voltage of the generator is improved, and the electric energy can realize the long-distance transmission. The greater the power, the farther the transmission distance, the corresponding transmission voltage is higher. For example, $500 \mathrm{kV}$ ultra high voltage transmission, 600 thousand to 1 million 500 thousand $\mathrm{kW}$ power of the electrical energy can be transported to a range of $400 \mathrm{~km}$ to $1000 \mathrm{~km}$ in the distance. $220 \mathrm{kV}$ voltage transmission, 100 thousand to 500 thousand $\mathrm{kW}$ power of the electrical energy can be transported to a range of $100 \mathrm{~km}$ to $300 \mathrm{~km}$ in the distance. $110 \mathrm{kV}$ voltage transmission, 10 thousand to 50 thousand $\mathrm{kW}$ power of the electrical energy can be transported to a range of $50 \mathrm{~km}$ to $100 \mathrm{~km}$ in the distance[6].

With the increase of transmission power and transmission distance, the voltage and capacity of the transformer are also getting higher and higher. In the system, power plants are usually built near coal mines or water rich areas. Through the large step up transformer, the power can be transported long distances to the industrial area or the vast rural areas. In the user area, a variety of capacity and voltage level of the transformer is used, in order to carry out power distribution. As mentioned above, a complete power system. Thus, in the power system, the transformer has an important role 
in the transmission and distribution of electrical energy. The low voltage power supply is usually used for $380 \mathrm{~V}$ and $220 \mathrm{~V}$. The voltage used by large high-voltage motors is $3 \mathrm{kV}$ or $6 \mathrm{kV}$. High voltage side voltage of distribution transformer is generally $6 \mathrm{kV}, 10 \mathrm{kV}, 35 \mathrm{kV}$, and there is also the $110 \mathrm{kV}$ voltage level in the large power grid [6].

\section{The Necessity of Temperature Measurement}

Transformer in the operation process, iron core, winding and steel structure to produce loss. These losses will produce heat, leading to the transformer temperature rise, insulation paper, insulation board, insulation pad and other insulation materials aging acceleration, the transformer's service life is shortened. The temperature limit of the transformer depends on the grade of the insulating material. Insulation material grade is refers to the heat resistance of the insulation material level, specific divided into the following 5 grades, A grade (105 degrees C), E grade (120 degrees $\mathrm{C}$ ), $\mathrm{B}$ grade (130 degrees $\mathrm{C}$ ), $\mathrm{F}$ grade (155 degrees $\mathrm{C}$ ), $\mathrm{H}$ grade (180 degrees $\mathrm{C}$ ). In the transformer, the insulation material is the weakest link, easy to be affected by the high temperature, and then accelerate the aging or damage. At present, most of the oil immersed transformer adopts the "A" grade insulation. Transformer oil temperature generally requires no more than 85 degrees celsius. Under normal circumstances, the temperature of transformer oil at the top is the highest, if the top oil temperature value beyond the prescribed scope, heat reduction measures need to be adopted. In order to make the temperature rise of the various parts of the transformer does not exceed the specified value, extend the service life of the transformer, the temperature measuring device must be installed, and monitoring the temperature and temperature change of the transformer [4].

Temperature controller is the use of "thermal imaging" principle of indirect measurement of winding temperature of the instrument. Its working principle is shown in figure 1.Temperature pack installed in the transformer tank top, it can sense the top oil temperature. In the indicating instrument, the displacement of the corrugated pipe is changed because of the transfer of the liquid in the capillary. The load current of the transformer bushing type current transformer is called Is. Current (Is) is adjusted by the current matching device to the current (I2). The current( I2) is added to the electric heating element in the corrugated tube. The heat generated by the electric heating element causes the displacement of the corrugated pipe to increase. The indication value of the temperature controller is determined by the top oil temperature and the load current of the transformer. For the electric heating element, it is assumed that the I2 produces a certain quantity of heat, which leads to the increment of the displacement of the bellows. The displacement increment leads to the change of the indication value. The temperature controller display value is equal to the actual value of the transformer top oil temperature. Because the transformer top oil temperature is approximately equal to the transformer winding (the hottest part) temperature. So, it can be approximated to reflect the temperature of the hottest part of the measured winding [6].

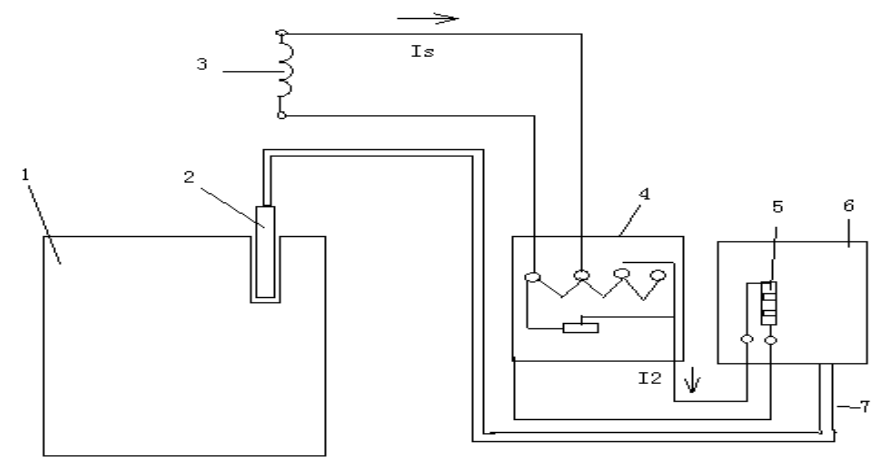

Fig. 1 Schematic diagram of working principle of temperature controller Note:1-Transformer.2-Iron thermometer.3-Current transformer. 4-Current matchingdevice. 5-Electric heating element.6-Indicating instruments.7- capillary. 


\section{Deficiency of Temperature Measuring Device}

In the transformer oil temperature measuring device, iron thermometer is placed in the thermometer hole (filled with transformer oil), and then sealed with screw threaded lid. The problem of tight seal has not been solved very well. In the temperature measurement holes, as the proportion of water is greater than the proportion of transformer oil, so the water will sink to the bottom of the hole, resulting in damage to the thermometer damp or swelling. This is not conducive to the transformer temperature monitoring.

\section{Filling Agent for Temperature Measuring Hole}

According to transformer oil, water density, thermal conductivity, dielectric strength, freezing point, volatile rate and long-term use temperature, developed a high-tech chemical material filling agent. The filling agent has the following characteristics: the density is two times larger than water; the thermal conductivity is three times higher than that of the insulating oil; the phenomenon is not cured under the condition of minus 50 degrees Celsius; there is no gasification phenomenon at 200 centigrade temperature. The high tech chemical material filling agent is a white paste. The main ingredient is organic silicone, the thermal conductivity is 26 times higher than that of transformer oil, the density is 2 times that of water. Because the paste body is very difficult to evaporate, and is applied to the actual, the risk of damage to the transformer thermometer is greatly reduced. The temperature measuring hole, replace the transformer oil with organic silicone, effectively prevent dampness, completely solve the problem of the damage temperature measuring device. Table 1 is the comparison of chemical and physical properties of transformer oil, water, organic silicone three substances.

Table 1. Transformer oil, water, organic silicone performance comparison table

\begin{tabular}{|c|c|c|c|c|c|}
\hline Performance test & transformer oil & water & $\begin{array}{l}\text { organic } \\
\text { silicone }\end{array}$ & Unit & Test Method \\
\hline Colour & $\begin{array}{l}\text { light yellow } \\
\text { transparent } \\
\text { liquid }\end{array}$ & $\begin{array}{l}\text { colorless } \\
\text { liquid }\end{array}$ & $\begin{array}{c}\text { the white } \\
\text { paste } \\
\text { body }\end{array}$ & ---- & Visual \\
\hline Main ingredients & alkane & Oxyhydrogen & $\begin{array}{l}\text { Organic } \\
\text { silicone }\end{array}$ & & \\
\hline $\begin{array}{l}\text { Thermal } \\
\text { conductivity }\end{array}$ & $0.10-0.13$ & 0.6 & 2.6 & $\mathrm{~W} / \mathrm{m} . \mathrm{k}$ & $\begin{array}{l}\text { ASTM } \\
\text { D5470 }\end{array}$ \\
\hline Density & 0.895 & 1 & 2.0 & $\mathrm{~g} / \mathrm{cm}^{3}$ & $\begin{array}{l}\text { ASTM } \\
\text { D5347 }\end{array}$ \\
\hline $\begin{array}{l}\text { Dielectric } \\
\text { strength }\end{array}$ & $>20$ & $<1$ & $>5$ & $\mathrm{kV} / \mathrm{mm}$ & $\begin{array}{c}\text { ASTM } \\
\text { D149 }\end{array}$ \\
\hline $\begin{array}{l}\text { Volume } \\
\text { resistivity }\end{array}$ & $10^{12}$ & $\leq 10^{6}$ & $10^{10}$ & $\Omega . \mathrm{cm}$ & \\
\hline Freezing point & -45 & 0 & -50 & ${ }^{\circ} \mathrm{C}$ & \\
\hline Volatilization rate & 135 & 100 & $<0.5$ & $\%$ & $200^{\circ} \mathrm{C} 24 \mathrm{~h}$ \\
\hline $\begin{array}{l}\text { Long term use } \\
\text { temperature }\end{array}$ & $-22 \sim 105$ & $0 \sim 100$ & $-50 \sim 200$ & ${ }^{\circ} \mathrm{C}$ & ----- \\
\hline
\end{tabular}

\section{Situation of Field Application}

Because the organic silicone density is greater than the transformer oil, the thermal conductivity is 26 times higher than that of transformer oil, and is sticky, so has the role of moisture. Figure 2 shows the comparison before and after the replacement of filler. 


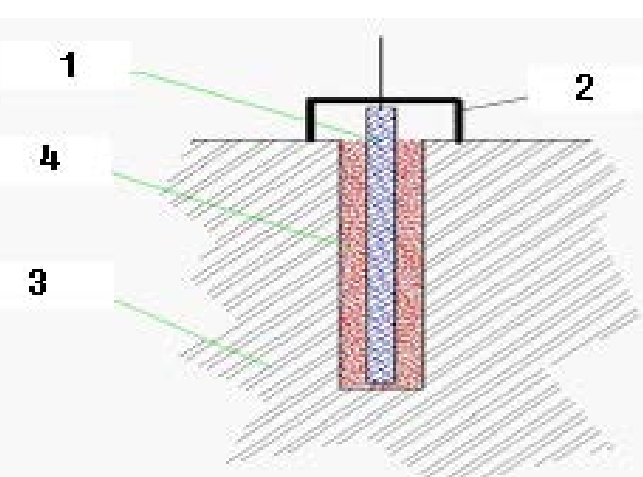

Schematic diagram prior to application

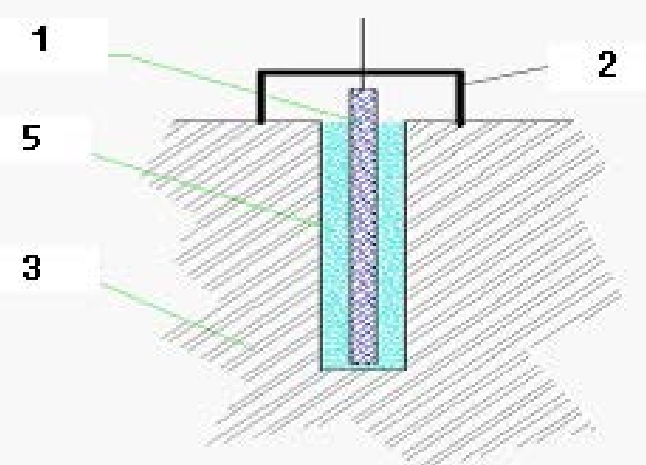

Schematic diagram after application

Fig. 2 comparison chart before and after application Note:1-Iron thermometer.2-Seal cover.3-Transformer main body. 4-transformer oil.5-Organic silicone

In November 19, 2012, Xinfu 66kV substation, 2\# main transformer overhaul, silicone fillers are applied to the test system of transformer temperature. So far, the transformer oil temperature monitor work were normal, the signal transmission were normal. In November 26, 2012, Tayu $66 \mathrm{kV}$ substation, 2\# main transformer overhaul, silicone fillers are applied to the test system of transformer temperature. organic silicone filler is applied to transformer temperature test system. So far, the transformer oil temperature monitor work were normal, no dampness accident. In December 11, 2012,Majiazi 66kV substation, 1\# main transformer overhaul, organic silicone filler is applied to transformer temperature test system. So far, the transformer oil temperature monitor work were normal.

\section{Conclusion}

In the past, in the transformer oil temperature measuring device, iron thermometer is placed in the thermometer hole (filled with transformer oil), and then sealed with screw threaded lid. The problem of tight seal has not been solved very well. In the temperature measurement holes, as the proportion of water is greater than the proportion of transformer oil, so the water will sink to the bottom of the hole, resulting in damage to the thermometer damp or swelling. This is not conducive to the transformer temperature monitoring. The high tech chemical material filling agent is a white paste. The main ingredient is organic silicone, the thermal conductivity is 26 times higher than that of transformer oil, the density is 2 times that of water. Because the paste body is very difficult to evaporate, and is applied to the actual, the risk of damage to the transformer thermometer is greatly reduced. The temperature measuring hole, replace the transformer oil with organic silicone, effectively prevent dampness, completely solve the problem of the damage temperature measuring device. Application of organic silicone antifreeze in the transformer temperature measurement system is good, and has wide popularization value and application prospect.

\section{References}

[1] Qiguo Dong. Power transformer fault diagnosis M. Beijing: China Electric Power Press, 2000.

[2] Huagang Chen. Electrical equipment preventive testing technology questions and answers. M: ". Beijing: Water Conservancy and electric power press, 1998.

[3] Huagang Chen. Electrical equipment preventive testing method M. Beijing: Water Conservancy and electric power press, 1999.

[4] Dunkui Cao. Transformer oil chromatographic analysis and fault diagnosis of M. Beijing: China power press, 2011.

[5] Shige Wang, Hongbi Zhong. Fault analysis and technical improvement of power transformer. M. 
Beijing: China Electric Power Press, 2004.

[6] Zhisong Yao ,Lei Yao . Structure, principle and application of new type distribution transformer. Mechanical Industry Press, 2008.4. 